Research Article

Genetics of Microorganisms

\title{
CRZ1 regulator and calcium cooperatively modulate holocellulases gene expression in Trichoderma reesei QM6a
}

Leonardo Martins-Santana ${ }^{1,2}$, Renato Graciano de Paula ${ }^{2,3}$, Adriano Gomes Silva ${ }^{1}$, Douglas Christian Borges Lopes $^{2}$, Roberto do Nascimento Silva ${ }^{2}$ and Rafael Silva-Rocha ${ }^{1}$ iD

${ }^{1}$ Universidade de São Paulo, Faculdade de Medicina de Ribeirão Preto, Departamento de Biologia Celular e Molecular e Bioagentes Patogênicos, Laboratório de Biologia Sistêmica e Sintética, Ribeirão Preto, SP, Brazil.

${ }^{2}$ Universidade de São Paulo, Faculdade de Medicina de Ribeirão Preto, Departamento de Bioquímica e Imunologia, Ribeirão Preto, SP, Brazil.

${ }^{3}$ Universidade Federal do Espírito Santo, Centro de Ciências da Saúde, Departamento de Ciências

Fisiológicas, Vitória, ES, Brazil.

\begin{abstract}
Trichoderma reesei is the main filamentous fungus used in industry to produce cellulases. Here we investigated the role of CRZ1 and $\mathrm{Ca}^{2+}$ signaling in the fungus $T$. reesei QM6a concerning holocellulases production. For this, we first searched for potential CRZ1 binding sites in promoter regions of key genes coding holocellulases, as well as transcriptional regulators and sugar and calcium transporters. Using a nearly constructed $T$. reesei $\Delta c r z 1$ strain, we demonstrated that most of the genes expected to be regulated by CRZ1 were affected in the mutant strain induced with sugarcane bagasse (SCB) and cellulose. In particular, our data demonstrate that $\mathrm{Ca}^{2+}$ acts synergistically with CRZ1 to modulate gene expression, but also exerts CRZ1-independent regulatory role in gene expression in $T$. reesei, highlighting the role of the major regulator $\mathrm{Ca}^{2+}$ on the signaling for holocellulases transcriptional control in the most part of cellulases genes here investigated. This work presents new evidence on the regulatory role of CRZ1 and $\mathrm{Ca}^{2+}$ sensing in the regulation of cellulolytic enzymes in $T$. reesei, evidencing significant and previously unknown function of this $\mathrm{Ca}^{2+}$ sensing system in the control key transcriptional regulators (XYR1 and CRE1) and on the expression of genes related to sugar and $\mathrm{Ca}^{2+}$ transport.
\end{abstract}

Keywords: Gene regulatory network, cellulase expression, transcriptional regulation, calcium sensing.

Received: July 30, 2019; Accepted: December 22, 2019.

\section{Introduction}

Cellulases and hemicellulases are key enzymes for the production of second generation ethanol production worldwide (Prasad et al., 2007). The promising utilization of agroindustrial residues as energy source has triggered a tremendous interest for engineering microorganisms for the low cost production of these enzymes aiming the conversion of complex plant biomass into fermentable sugars, which in turn could be used for ethanol production (Druzhinina and $\mathrm{Ku}-$ bicek, 2017; Seppälä et al., 2017; Martins-Santana et al., 2018). In this sense, the saprophyte organism T. reesei is one of the main filamentous fungi used in industry to produce these enzymes (Druzhinina and Kubicek, 2017). Despite the great potential of this fungus for high performance cellulase

Send correspondence to Rafael Silva-Rocha. Universidade de São Paulo, Faculdade de Medicina de Ribeirão Preto, Departamento de Biologia Celular e Molecular e Bioagentes Patogênicos, Laboratório de Biologia Sistêmica e Sintética, Avenida Bandeirantes, Vila Monte Alegre 14049-900, Ribeirão Preto, SP, Brazil. E-mail: silvarochar@gmail.com. and hemicellulase production, the regulatory network controlling this system is relevant for studying and not fully understood yet. Additionally, the comprehension of transcriptional networks that coordinate the transcription of holocellulases is one of the main foci to allow a viable enzyme production at industrial scale (Borin et al., 2018).

T. reesei possesses a great capability for enzyme secretion (Schmoll et al., 2016) but few cellulases and hemicellulases genes. Even harboring this limited gene repertoire, its regulation is highly precise and controlled at molecular level by external signals (Gupta et al., 2016). Several transcription factors (TFs) are now known for exerting modulation on the expression levels of holocellulases genes (Paula et al., 2018). In this sense, the regulatory network that encompasses cell wall deconstruction is under regulation of positive regulators, such as XYR1 (Stricker et al., 2006), ACEII (Aro et al., 2001), LAE1 (Seiboth et al., 2012), BglR (Nitta et al., 2012), VEL1 (Karimi et al., 2014), HAP 2/3/5 complex (Zeilinger et al., 2001) and other proteins which play a negative control in such process, as CRE1 (Portnoy et al., 2011), 
ACEI (Aro et al., 2003) and RCE1(Cao et al., 2017). Additionally, it is already known that xylanases genes may also be targets of regulation by TFs, such as Xpp1 (Derntl et al., 2015b) and SxlR (Liu et al., 2017).

The complex network that coordinates holocellulases expression in $T$. reesei is also under regulation of nutritional variability. Therefore, differential gene expression was discussed by Castro et al. (2014b) and Antoniêto et al. (2016) in studies that reported the influence of carbon source on holocellulases transcription. Robust techniques like RNA sequencing have already highlighted the importance of sugar availability on the regulation mediated by TFs in $T$. reesei (Castro et al., 2016), evidencing the growing need of elucidating deep layers of regulation in this fungus.

Nutritional requirements and $\mathrm{pH}$ stress conditions control are targets of research among a wide number of fungal species, such as Neurospora crassa (Virgilio et al., 2017), Trichoderma harzianum (Moreno-Mateos and Codo, 2007) and T. reesei (He et al., 2014). However, the influence of several stress conditions, such as the effect of ion concentration exposure $\mathrm{n}$ transcription, still remain poorly understood in the industrial workhorse $T$. reesei. Despite not completely elucidated, recent studies have demonstrated the balance mediated by signaling pathways to keep physiological homeostasis when $T$. reesei is exposed to $\mathrm{Ca}^{2+}$ stress through Calmodulin-Calcineurin downstream activation steps (Chen et al., 2016).

CRZ1 (Calcineurin-responsive zinc finger 1) is a key target of Calcineurin $(\mathrm{CN})$ in fungal cells and is a well-conserved homologus protein in several fungi species (Zhang et al., 2013; Thewes 2014; Chow et al., 2017), being responsible for many coordinated cellular functions. In Saccharomyces cerevisiae, the deletion of this protein resulted in hypersensitivity to chloride and chitosan, as well as mating and transcriptional response to alkaline and stress conditions defects (Zakrzewska et al., 2005). In another crzl mutant yeast, Candida albicans, the knockout effect was correlated to changes on the pattern of sensitiveness to $\mathrm{Ca}^{2+}, \mathrm{Mn}^{2+}$ and $\mathrm{Li}^{2+}$, as well as in hypersensitiveness to azole molecules (Santos and de Larrinoa, 2005). The role of CRZ1 in filamentous fungi is already described for some species, and in this context, for the pathogenic and opportunistic Aspergillus fumigatus, crzl homologue (crzA) knockout resulted in virulence attenuation and developmental defects in both hyphal morphology and conidiation (Soriani et al., 2008). Effects of CRZ1 in filamentous fungi were also mentioned for Cryptococcus neoformans, where growth at temperatures higher than $39^{\circ} \mathrm{C}$ was compromised in $\mathrm{crzl}$ knockout strains, as well as its absence resulted in sensitiveness to cell wall perturbing agents (Lev et al., 2012; Chow et al., 2017).

In $T$. reesei, the role of $\mathrm{Ca}^{2+}-\mathrm{CaM} / \mathrm{CN} / \mathrm{CRZ} 1$ pathway is poorly studied and established in comparison to other fungal species. Yet, it is already known that the $\mathrm{Ca}^{2+}$ signaling pathway may exert effects on the modulation of holocellulases gene expression in the industrial strain of $T$. reesei RUT-C30 (Chen et al., 2016). Therefore, Chen et al. (2016) showed that the regulation of relevant industrial genes, such as cbhl, egl and $x y r l$ genes were negatively modulated in the absence of
CRZ1 when calcium was added to a cellulose-supplemented medium.

Despite the evidence that CRZ1 and $\mathrm{Ca}^{2+}$ may influence holocellulases expression, these results were obtained when the industrial strain of $T$. reesei RUT-C30 was evaluated in different environmental conditions. Yet, this strain harbors a deletion of approximately 85 kilobases $(\mathrm{kb})$ from the $T$. reesei genome which includes the crel locus, resulting in phenotypes that are independent on CRE1-mediated influence (Seidl et al., 2008; Mello-de-Sousa et al., 2014).

The role of CRZ1 and $\mathrm{Ca}^{2+}$ have not been investigated in the wild type strain of $T$. reesei (QM6a), which harbors the full set of regulatory components in its genome. In order to elucidate this, we investigated the role of $\mathrm{CRZ1} / \mathrm{Ca}^{2+}$ in a wild set genes coding for TFs, enzymes, and transporters related to holocellulose deconstruction. We were able to identify CRZ1 transcription factor binding sites (TFBS) in promoter regions of holocellulases differentially expressed genes after $T$. reese $i$ QM6a exposure to SCB and cellulose as carbon source. Additionally, we reported the fundamental role of CRZ1 on transcriptional regulation of such genes, as well as demonstrating that $\mathrm{Ca}^{2+}$ can cooperatively with $\mathrm{CRZ1}$, induce or repress the transcription of holocellulase genes. These findings bring evidence of $\mathrm{Ca}^{2+}$ as a pivotal ion in the control of stimuli regarding expression of sugar and calcium transporters in T. reesei QM6a cells in a CRZ1-independent but synergistic mechanism.

\section{Material and Methods}

\section{Analysis of promoter sequences}

For the identification of potential CRZ1-binding elements, sequences of $1 \mathrm{~kb}$ upstream of the ATG from the Open Reading Frames (ORFs) of the promoter of TFs, holocellulases and transporter genes, as well as for homologs of calcium and sugar transporters were retrieved from the reference genome of T. reesei. Next, Position Weight Matrix (PWM) from CRZ1 of $S$. cerevisiae were obtained from YeTFaSCo (The Yeast Transcription Factor Specificity Compendium) collection (De Boer and Hughes, 2012) and used to calculate the scores in all promoters of $T$. reesei. Scores greater than zero were selected and normalized, revealing sequence with the higher probability of harboring a functional cis-regulatory element than a random motif. The normalization function was: Score $_{\text {Normalized }}(\mathrm{Xij})=\operatorname{Score}(\mathrm{Xij}) /$ MaxScore, being $\mathrm{X}$ the set of sense and antisense upstream regulatory sequences; $i$ the sequence index; $j$ the initial position for score calculation; and MaxScore the maximum score possible of the CRZ1 TF PWM. Through histogram analyses of the normalized score, we established a threshold of 0.8 , using a comparison between real sequences and a control dataset formed by random sequences. Finally, this threshold was used to map potential cis-regulatory elements for CRZ1 in the target of interest.

\section{Strains and media}

T. reesei strain QM6a $\Delta$ tmus 53 spyr4 was used as wild type (WT) strain in this study and it was obtained from the Institute of Chemical Engineering (Viena University of Tech- 
nology, Viena, Austria) (Derntl et al., 2015a). The strain was maintained in MEX medium (3\% (w/v) malt extract and 2\% (w/v) agar)) at $30{ }^{\circ} \mathrm{C}$ supplemented with $5 \mathrm{mM}$ uridine for pyr4 auxotrophic selection (Gruber et al., 1990). T. reesei QM6a $\Delta$ tmus53 $\Delta$ pyr4 wild type and $\Delta c r z 1$ (constructed as described below) strains were grown on MEX medium at 30 ${ }^{\circ} \mathrm{C}$ for 7-10 days until complete sporulation. For gene expression assays, approximately $10^{6}$ spores $/ \mathrm{mL}$ from both strains were inoculated in Mandels Andreotti (MA) medium (Schmoll et al., 2009) containing 1\% (w/v) sugarcane bagasse, cellulose (Avicel, Sigma-Aldrich) or glycerol as carbon source. For induction of gene expression in the presence of sugarcane bagasse, the substrate in natura, gently donated by Nardini Agroindustrial Ltd., Vista Alegre do Alto, São Paulo, Brazil, was previously prepared according to Souza et al. (2011). Mycelia from both strains (WT and $\Delta c r z l$ ) were pre-grown in MA medium supplemented with $1 \%$ (w/v) glycerol, in the presence and in the absence of $10 \mathrm{mM} \mathrm{CaCl}_{2}$, in orbital shaker at $30{ }^{\circ} \mathrm{C}$ for $24 \mathrm{~h}$ under $200 \mathrm{rpm}$. In these assays, MA medium presented a basal concentration of $2.6 \mathrm{mM} \mathrm{Ca}^{2+}$ to ensure the maintenance of fungal cellular viability and growth. The obtained mycelia were harvested and transferred to MA medium supplemented with $1 \%(\mathrm{w} / \mathrm{v})$ sugarcane bagasse or cellulose (Avicel, Sigma-Aldrich) in orbital shaker at $200 \mathrm{rpm}, 30^{\circ} \mathrm{C}$ for $8 \mathrm{~h}$. All experimental conditions described were performed with three biological replicates. The resulting mycelia were collected by filtration, frozen in liquid nitrogen and stored at $-80^{\circ} \mathrm{C}$ for RNA extraction procedures.

\section{Construction of crz1 deletion cassette and T. reesei genetic transformation}

Deletion of crzl gene from T. reesei QM6a $\Delta$ tmus 53 spyr4 was performed as previously described (Schuster et al., 2012). For this, we designed a deletion cassette containing the pyr4 gene (orotidine-5'-phosphate decarboxylase gene of $T$. reesei Trire_74020) as auxotrophic selection marker. All sequences of this cassette are available at the $T$. reesei genome database (https://mycocosm.jgi.doe.gov/Trire2/Trire2.home.html) and the primers used in this study were designed to contain overlapping regions to the components sequence of the cassette (Table $\mathrm{S} 1$ ). The deletion cassette is composed by 1226 base pairs (bp) upstream to the 5, crzl CDS flanking region (Trire_36391) and $1465 \mathrm{bp}$ downstream to the crzl ORF 3' flanking region. These two sequences flanks pyr4 gene sequence, which consists of $1100 \mathrm{bp}$ upstream and $1000 \mathrm{bp}$ downstream to the pyr 4 CDS sequence in $T$. reseei's genome. Individual fragments were amplified at $60^{\circ} \mathrm{C}$ with Phusion $\mathbb{R}$ High-Fidelity Polymerase (New England Biolabs) using $T$. reesei QM6a $\Delta$ tmus53 spyr4 genomic DNA as template, according to the manufacturer's instructions. The PCR fragments were purified using QIAquick PCR Purification Kit (Qiagen). The assembly of the components was performed through homologous recombination in $S$. cerevisiae, as previously reported (Colot et al., 2006; Gietz and Schiestl, 2007; Collopy et al., 2010). For this purpose, we used the pRS426 shuttle vector (Christianson et al., 1992) previously treated with EcoRI and XhoI enzymes (New England Biolabs). These treatments resulted in the occurrence of cohesive ends correspondent to the external extremities in the primers used to obtain the 5' and 3' pyr4 ORF flanker regions of the deletion cassette. Yeast transformation procedures were performed as described by Gietz and Schiestl (2007) in the yeast

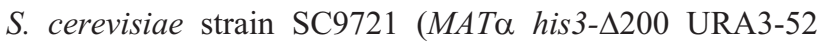
leu2 $\Delta 1$ lys $2 \Delta 202$ trp1 $\Delta 63$ ) (Fungal Genetic Stock Centerwww.fgsc.net). The transformants were selected on YNB $(0.7 \%(\mathrm{w} / \mathrm{v})$ yeast nitrogen base (Sigma) supplemented with $2 \%$ glucose, $0.1 \mathrm{~g} / \mathrm{L}$ lysine, $0.05 \mathrm{~g} / \mathrm{L}$ histidine, $0.1 \mathrm{~g} / \mathrm{L}$ leucine, and $0.1 \mathrm{~g} / \mathrm{L}$ tryptophan in the absence of uracil.

To confirm the complete assembly of the cassette, genomic DNA of $S$. cerevisiae was extracted according to Goldman et al. (2003) and Sambrook and Russel (2001). Primers 5'Pcrzl and 3'Tcrzl (Table S1) were used to amplify the deletion cassette from the yeast genome using Phusion ${ }^{\circledR}$ High-Fidelity Polymerase (New England Biolabs) according to manufacturer's instructions. The resultant amplicons were purified using QIAquick PCR Purification Kit (Qiagen) and were stored at $-20^{\circ} \mathrm{C}$ until $T$. reesei transformation. Transformation of $T$. reese $i$ was performed using $10 \mu \mathrm{g}$ of the linearized deletion cassette by protoplast fusion methodology (Gruber et al., 1990). Transformants were selected in MA medium plates supplemented with $1 \%(\mathrm{w} / \mathrm{v})$ glucose and $2 \%$ (w/v) agar (Sigma-Aldrich). Selection was carried out in the absence of uridine. Genomic DNA was extracted to confirm the cassette integration (Vitikainen et al. (2010). To verify the correct orientation of cassette positioning in the positive transformants, it was performed two PCR reactions with primers 5'Pcrzl Check1/3'pyr4 Check 1 and 5'pyr4 Check 2/3'Tcrzl Check 2 (Table S1, Figure S1 A-B), which are specific for pyr4 annealing regions and for external annealing regions into promoter and terminators sequences. A PCR to confirm the deletion of the $\mathrm{crzl}$ from $T$. reesei genome was performed using the primers 5' $\mathrm{crzl}$ ORF and 3' $\mathrm{crzl}$ ORF (Table S1, Figure S1 C). Null expression of $c r z 1$ gene was also investigated with a quantitative PCR with total RNA using the primers PF $c r z 1$ qRT-PCR and PR $c r z 1$ qRT-PCR (Table S1, Figure S1 D).

\section{Gene expression analysis by Real-Time PCR}

For gene expression analysis, $1 \mu \mathrm{g}$ of total RNA of each culture condition was treated with DNAse I (Sigma-Aldrich). cDNA samples were synthesized using Maxima First Strand cDNA Synthesis kit (ThermoFisher Scientific) and posteriorly diluted 1:50 in DEPC water. For gene expression levels detection, SsoFast EvaGreen ${ }^{\circledR}$ Supermix (Bio-Rad) was used according to the manufacturer's instructions. A list of target genes whose expression were evaluated are available in Table $\mathrm{S} 2$. Reactions were carried out at $95^{\circ} \mathrm{C}$ for $10 \mathrm{~min}$, followed by 40 cycles at $95^{\circ} \mathrm{C}$ for $10 \mathrm{~s}$ and $60^{\circ} \mathrm{C}$ for $30 \mathrm{~s}$ in a Bio-Rad CFX96 Real-Time System coupled to a C1000 Thermal Cycler (BioRad). Expression of target genes was normalized by the $\beta$-actin endogenous transcript levels for each RNA prevenient from the culture conditions. For sugarcane bagasse and cellulose expression quantification (for both in presence or in the absence of $10 \mathrm{mM}$ calcium chloride) the $2^{-\Delta \Delta \mathrm{Ct}}$ 
method was employed (Livak and Schmittgen, 2001). The quantification was relative to transcript levels observed in the WT and $\Delta c r z 1$ strains grown in glycerol for $24 \mathrm{~h}$ (for both in the presence or in the absence of $10 \mathrm{mM}$ calcium chloride).

\section{Enzymatic activity assays}

The activity of $\beta$-glucosidases and $\beta$-xylosidases were measured as the capacity of hydrolyzing pNPG and pNPX substrates as previously described (Hideno et al., 2011; Lopes et al., 2012; Castro et al., 2014b). Endoglucanase activity was determined using carboxymethylcellulose (CMC) (Sigma-Aldrich) as substrate in microplates, in a protocol adapted from Xiao et al. (2005). We solubilized 1\% (w/v) $\mathrm{CMC}$ in $\mathrm{pH} 4.8$ sodium acetate buffer. After addition of $30 \mu \mathrm{L}$ of culture supernatant, reactions were incubated for $30 \mathrm{~min}$ at $50{ }^{\circ} \mathrm{C}$. After this time, $60 \mu \mathrm{L}$ of 3,5-dinitrosalicylic acid (DNS) were added to the reaction and the mixture were submitted to incubation for $5 \mathrm{~min}$ at $95{ }^{\circ} \mathrm{C}$ (Miller, 1959). Absorbance at $540 \mathrm{~nm}$ was used for samples measurements. One enzyme unit was defined as the amount of enzyme capable of releasing $1 \mu \mathrm{mol}$ of reducing sugar per minute. Endoxylanases activity was determined using xylan from beechwood (Sigma-Aldrich) solubilized in pH $5.0100 \mathrm{mM}$ sodium acetate buffer as substrate. Reactions were performed with $25 \mu \mathrm{L}$ of the culture supernatant and $50 \mu \mathrm{L}$ of substrate at $50{ }^{\circ} \mathrm{C}$ for $30 \mathrm{~min}$. After incubation, we mixed $75 \mu \mathrm{L}$ of DNS and heated the reactions at $95^{\circ} \mathrm{C}$ for $5 \mathrm{~min}$ to visualize the effects of reduction of dinitrosalicylic acid. Absorbances were carried at $540 \mathrm{~nm}$. One unit of enzyme was defined as the amount of enzyme capable of releasing $1 \mu \mathrm{mol}$ of reducing sugar per minute (Castro et al., 2014a).

A

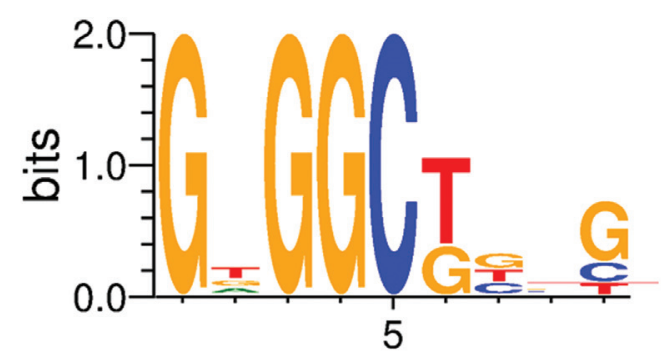

B

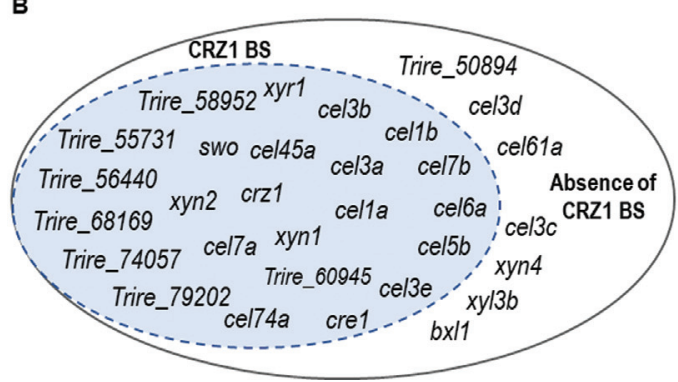

\section{Results}

\section{Identification of CRZ1 binding motifs in T. reesei promoters}

We first investigated the existence of putative binding sites for CRZ1 in $T$. reesei holocellulases and calcium and sugar transporter promoters using the defined sequence for $S$. cerevisiae. For this, we selected 30 genes related to biomass degradation in plant cell wall through proteins secreted by $T$. reesei, such as cellulases, hemicellulases and sugar transporters, as well as calcium transporters and TFs that play a significant role in this process. In this sense, we were able to identify potential cis-regulatory elements for CRZ1 in 24 of these sequences, as represented in Figure 1A-B. Interestingly, the major numbers of potential cis-regulatory elements for CRZ1 were observed in crel and cel7a genes, as well as for Trire_56440 and Trire_58952 calcium transporter proteins promoters (Figure $1 \mathrm{C}$ ). We also observed that the promoter of crzl gene harbors 3 potential cis-regulatory elements in antisense orientation, suggesting that CRZ1 plays autoregulation at transcriptional level (Figure 1C). Taken together, these results evidenced the existence of putative binding sites for CRZ1 in several genes related to gene regulation, biomass and calcium transport, highlighting the potential role of this TF in the regulation of these genes.

\section{$\mathrm{CRZ1}$ and $\mathrm{Ca}^{2+}$ synergistically regulate TFs and cellobiohydrolase coding genes}

Once we identified putative binding sites for CRZ1 at promoter regions of the genes of interest, we tried to understand how carbon source, as well as $\mathrm{Ca}^{2+}$ supplementation,

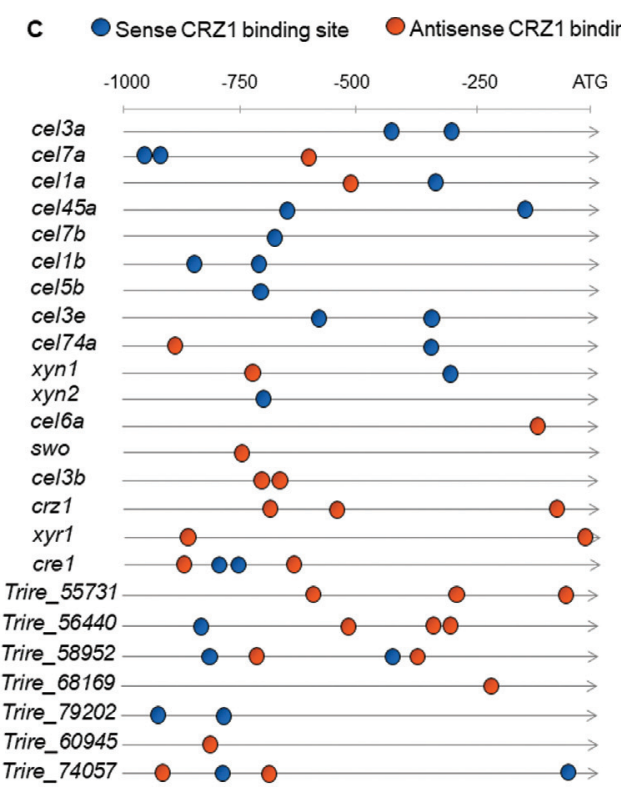

Figure 1 - (A) DNA Consensus sequence of CRZ1 binding in T. reesei obtained through bioinformatics analysis. (B) Representative scheme of genes which harness CRZ1 BS (CRZ1 binding sites) at genomic level. (C) in silico Identification of CRZ1 BS in promoter regions of holocellulases and calcium and sugar transporter genes in T. reesei. Blue spheres indicate that those sequences (previously shown in 1A) have been found in sense orientation, and orange spheres represent the antisense sequences occurrence. The number of spheres represents the absolute frequency that these sequences were observed in bioinformatics analysis. 
could modulate the transcription of these genes in the wild type and $\Delta$ crzl mutant strain. In this sense, we observed that under exposure to $\mathrm{SCB}$, the expression of $x y r 1$ was positively modulated in the wild type strain of $T$. reesei by the supplementation of $10 \mathrm{mM} \mathrm{Ca}^{2+}$ to the medium (Figure $2 \mathrm{~A}$ ). However, this stimulatory effect was lost in the $T$. reese $i$ $\Delta$ crzl strain, indicating that this process was completely dependent on CRZ1. Additionally, the same effect was observed when Avicel was used as inducer (Figure S2). In the case of crel, we observed only minor changes in the expression of this TF under all conditions tested, with a small but significant reduction in its expression in the wild type strain upon $\mathrm{Ca}^{2+}$ induction or between wild type and $\Delta$ crzl strain without the exposure to this ion (Figure 2B). Yet, when its expression was assayed under Avicel exposure, no significant change was observed between any condition analyzed (Figure S2 B). It is worth to notice that while putative CRZ1 binding sites were identified at both $x y r l$ and crel promoters (Figure 1C), only the former seems to be significantly regulated by this TF under the conditions analyzed here.

Since we identified putative CRZ1 binding sites in $\mathrm{crz} 1$ promoter, we were also interested in investigate how CRZ1mediated autoregulation in $T$. reesei was related to carbon

A
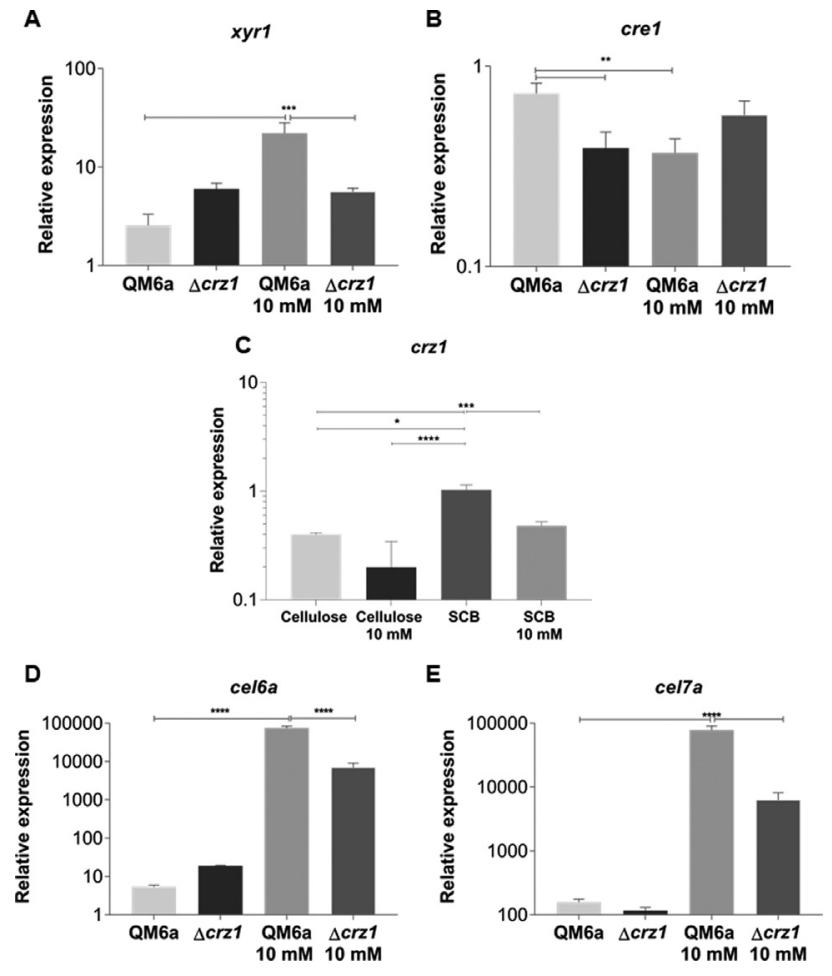

$c r 21$

Figure 2 - Analysis of differential expression of the transcription factors XYR1 (A), CRE1(B), and CRZ1 (C) of T. reesei and of cellobiohydrolases CEL6A (D) and CEL7a (E) from QM6a and $\triangle$ crz1 T. reesei strains after 8 $\mathrm{h}$ of growing in SCB and SCB supplemented with $10 \mathrm{mM} \mathrm{Ca}^{2+}$. CRZ1 expression in the presence of cellulose and the effect caused by calcium on this induction is also shown in panel C. Expression values are represented as $\log _{10}$ means of three biological replicates with standard deviation normalized by glycerol expression levels at the same condition. Statistical significance is represented as asterisks, considering p-value as $<0.05(*)$, $<0.01(* *),<0.001(* * *)$ and $\mathrm{p}<0.0001(* * * *)$. source availability. In this sense, Figure $2 \mathrm{C}$ shows the result only for wild type strain of $T$. reesei with or without $\mathrm{Ca}^{2+}$ exposure. As shown by the figure, under SCB induction, the expression levels of $\mathrm{crzl}$ were higher than those obtained after cellulose induction. In addition, after supplementation of the medium with $10 \mathrm{mM} \mathrm{Ca}^{2+}$, the expression of this gene decreased in the presence of SCB, suggesting that $\mathrm{Ca}^{2+}$ may exert a modulatory effect on CRZ1 autoregulation.

Since we observed that $x y r l$ expression was induced by $\mathrm{Ca}^{2+}$ in a CRZ1 dependent manner, we next evaluated the role of these two components in the expression of cel6a and cel7a, the two major cellobiohydrolases from $T$. reesei. We found that $\mathrm{Ca}^{2+}$ supplementation resulted in a significant increase in cel6a and cel7 $a$ induction both under exposure to SCB (Figure 2D-E) for cel6a in Avicel (Figure S2 C-D). Additionally, deletion of crzl resulted in a significant reduction in this stimulatory effect, even though this was not completely abolished. Taken together, these results indicated that CRZ1 and $\mathrm{Ca}^{2+}$ synergistically control the expression of celobiohydrolases coding genes under SCB and Avicel exposure, and highlight that an additional $\mathrm{Ca}^{2+}$-dependent and CRZ1- synergistic mechanism could take part in this process.

\section{Other cellulases genes are also key of regulation by $\mathrm{CRZ1}$ and $\mathrm{Ca}^{2+}$}

Since we observed that CRZ1 is capable to modulate xyrl expression levels, we next investigated how the expression of xylanase coding genes was modulated as a result of such effect mediated by CRZ1. Thus, under exposure to SCB, we observed a significant increase on the expression of these genes induced by the simple supplementation with $\mathrm{Ca}^{2+}$ (Figure 3A-E). Additionally, the deletion of crzl was not able to result in differences on the expression of these genes, but we detected a loss in their expression in the $T$. reesei $\Delta$ crzl strain after $\mathrm{Ca}^{2+}$ supplementation. Taking in advantage of these results, our findings suggest that the regulation of xylanase genes under SCB exposure is modulated by $\mathrm{Ca}^{2+}$ in a synergistically CRZ1-dependent mechanism, highlighting the relevance of this TF on a complete background concerning gene regulation in the wild type strain of this fungus. Interestingly, no effects were observed when Avicel was used as inducer, since none differential expression was detected under cellulose exposure (Figure S3 A-D).

The $\mathrm{Ca}^{2+}$ - CRZ1-independent but synergistic mechanism was also observed when we analyzed the expression of some $\beta$-glucosidases coding genes after SCB and cellulose induction (Figure 4A-G, Figure S4 A-F). Regarding $\beta$-glucosidases regulation, such mechanism of cooperation was so remarkable that only one of the studied genes (cebl3b) was modulated by CRZ1 alone (without $\mathrm{Ca}^{2+}$ ) (Figure 4D). Interestingly, in opposite to the main cellulases of $T$. reesei (cel6a and cel7a), $\beta$-glucosidases gene control tends to respond more effectively to cellulose stimuli, highlighting the role of these enzymes on plant cell wall deconstruction. It is also worth to notice that $\beta$-glucosidases coding genes were a class of genes which we identified a vast number of putative CRZ1 binding sites in our in silico analysis, providing us an hypoth- 

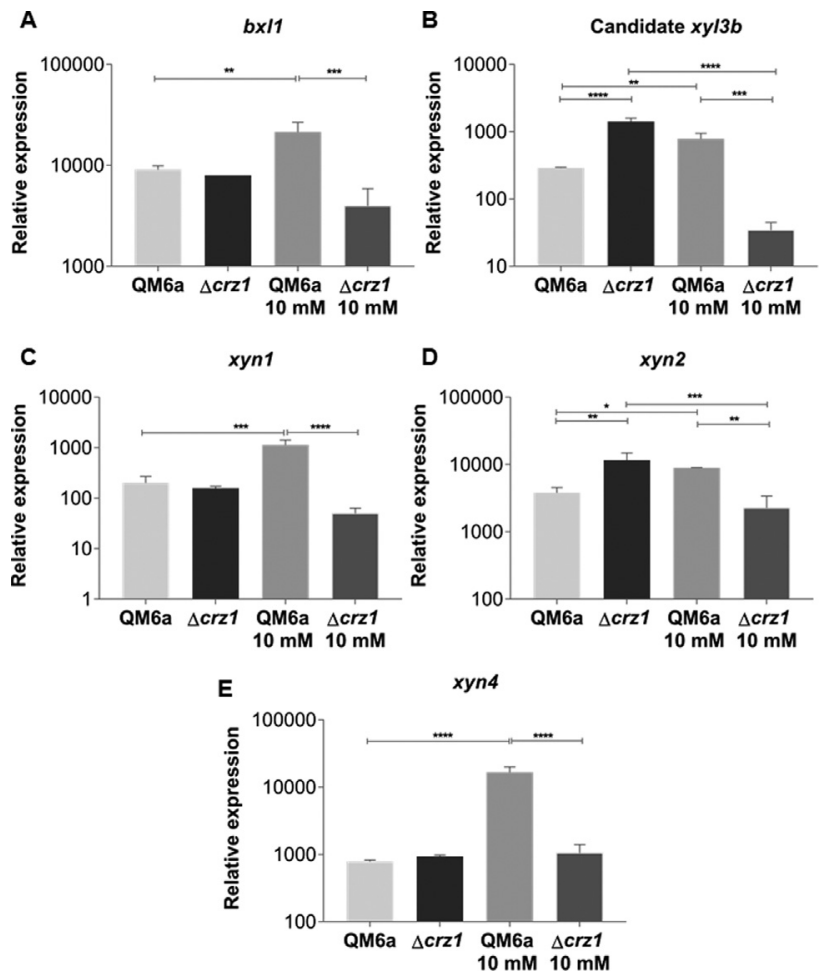

Figure 3 - Relative expression of the $\beta$-xylosidase 1 and (A) the candidate $x y l 3 b$ xylosidase (B) and of the endoxylanases xyn 1 (C), xyn 2 (D) and xyn 4 (E) genes from QM6a and $\Delta$ crz1 T. reesei strains after $8 \mathrm{~h}$ of induction $\mathrm{SCB}$ and SCB supplemented with $10 \mathrm{mM} \mathrm{Ca}^{2+}$. Expression values are represented as $\log _{10}$ means of three biological replicates with standard deviation normalized by glycerol expression levels at the same condition. Statistical significance is represented as asterisks, considering p-value as $<0.05\left(^{*}\right),<0.01(* *),<0.001(* * *)$ and $\mathrm{p}<0.0001(* * * *)$.

esis of why these genes are more responsible to cellulose than other known strongly expressed genes (cellobiohydrolases).

The most heterogeneous effect on holocellulases expression was noticed for glucanase coding genes expressed in $\mathrm{SCB}$, as shown by Figure $5 \mathrm{~A}-\mathrm{D}$. In this condition, we observed a $\mathrm{Ca}^{2+}$-CRZ1-independent decrease on endoglucanases expression (Figure 5A), a synergistic $\mathrm{Ca}^{2+}-\mathrm{CRZ1-}$ independent effect which resulted in a increase on expression (Figure 5B, D) and finally, a positive modulation exclusively mediated by CRZ1 which loses its potential in a $\mathrm{Ca}^{2+}$-synergic mechanism (Figure 5C). Interestingly, after cellulose induction, the $\mathrm{Ca}^{2+}-\mathrm{CRZ1-independent} \mathrm{mechanism} \mathrm{was} \mathrm{capable} \mathrm{to}$ potentialize the expression of only cel7b gene (Figure S5 B).

The effect of $\mathrm{Ca}^{2+}$ and the deletion of $\mathrm{crz} 1$ on accessory proteins expression was also investigated in our study, as shown for the lytic polysaccharide monooxygenases (LPMO) cel61a and swo (swollenin, an expansin-like protein) genes. In this way, we also observed the effect of a synergistic $\mathrm{Ca}^{2+}$ CRZ1-independent mechanism that may positively regulate the expression of these genes in both SCB (Figure 5E-F) and cellulose induction (Figure S5 E-F), highlighting the role of both CRZ1 and $\mathrm{Ca}^{2+}$ on the regulation of accessory proteins required for lignocellulose deconstruction.
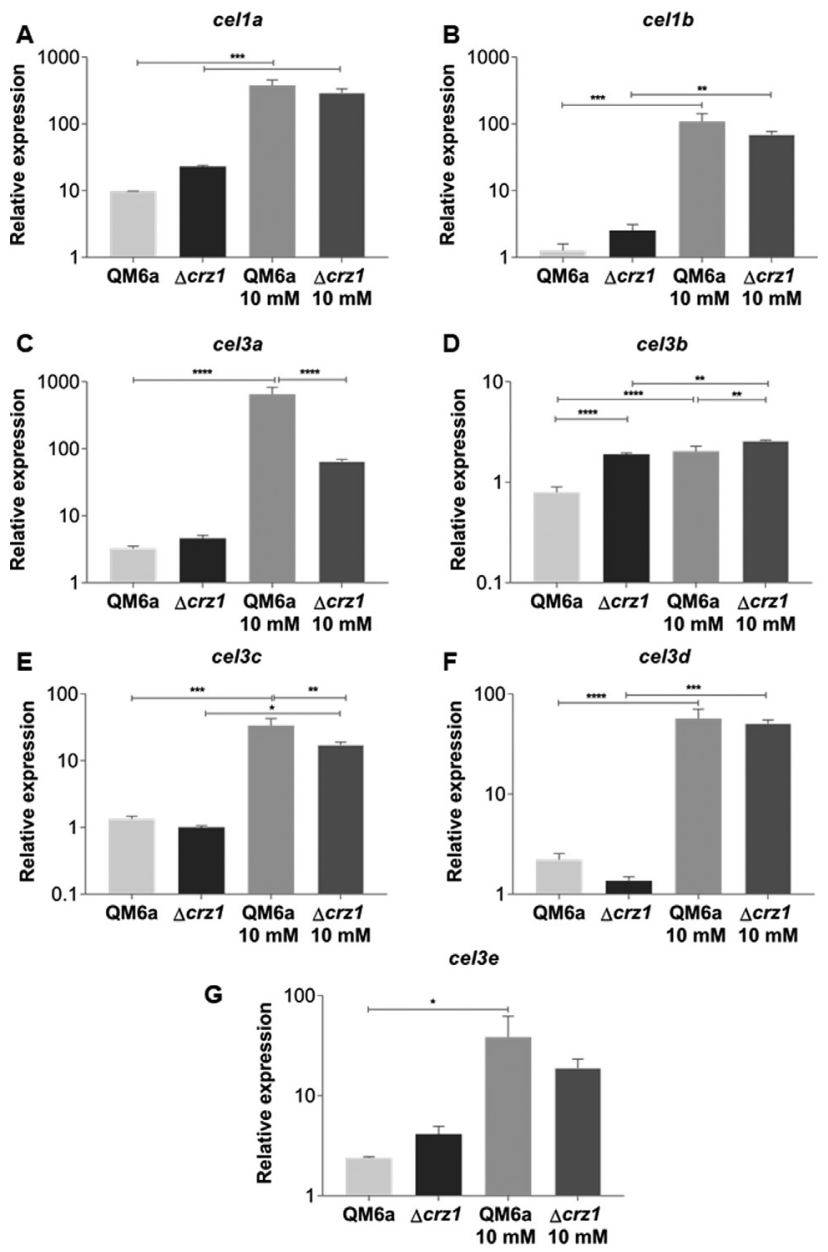

Figure 4 - qRT-PCR results for differential expression analysis of the $\beta$-glucosidases genes of $T$. reesei in the QM6a and $\Delta$ crz1 strains after $8 \mathrm{~h}$ of growing in SCB supplemented or not with $10 \mathrm{mM} \mathrm{Ca}^{2+}$. Expression values are represented as $\log _{10}$ means of three biological replicates with standard deviation normalized by glycerol expression levels at the same condition. Statistical significance is represented as asterisks, considering p-value as $<0.05(*),<0.01(* *),<0.001(* * *)$ and $\mathrm{p}<0.0001(* * *)$.

\section{Calcium and sugar transporters are regulated by CRZ1 in the presence of $\mathrm{Ca}^{2+}$}

Since the role of $\mathrm{Ca}^{2+}$ is clearly related to the CRZ1 regulatory role in $T$. reesei (Chen et al., 2016), we decided to investigate whether calcium transporters were target of modulation by CRZ1. After both SCB and cellulose growth, we observed that the deletion of $\mathrm{crzl}$ elicited a loss in transcription of these genes in the presence of SCB (Figure 6B-C) while it boosted the expression of the same genes after cellulose induction (Figure S6 B-D). In spite of CRZ1-independent modulator effect, it is also worth to notice that $\mathrm{Ca}^{2+}$ synergistically to this TF lacking were able to cause a decrease on the expression of such genes predominantly in SCB in comparison to cellulose (Figure 6A-C, Figure S6 B). Interestingly, our in silico analysis also evidenced the occurrence of putative CRZ1 binding sites in promoter regions of these genes, suggesting that calcium homeostasis is precisely regulated at genomic levels by CRZ1, mainly under stress conditions. 

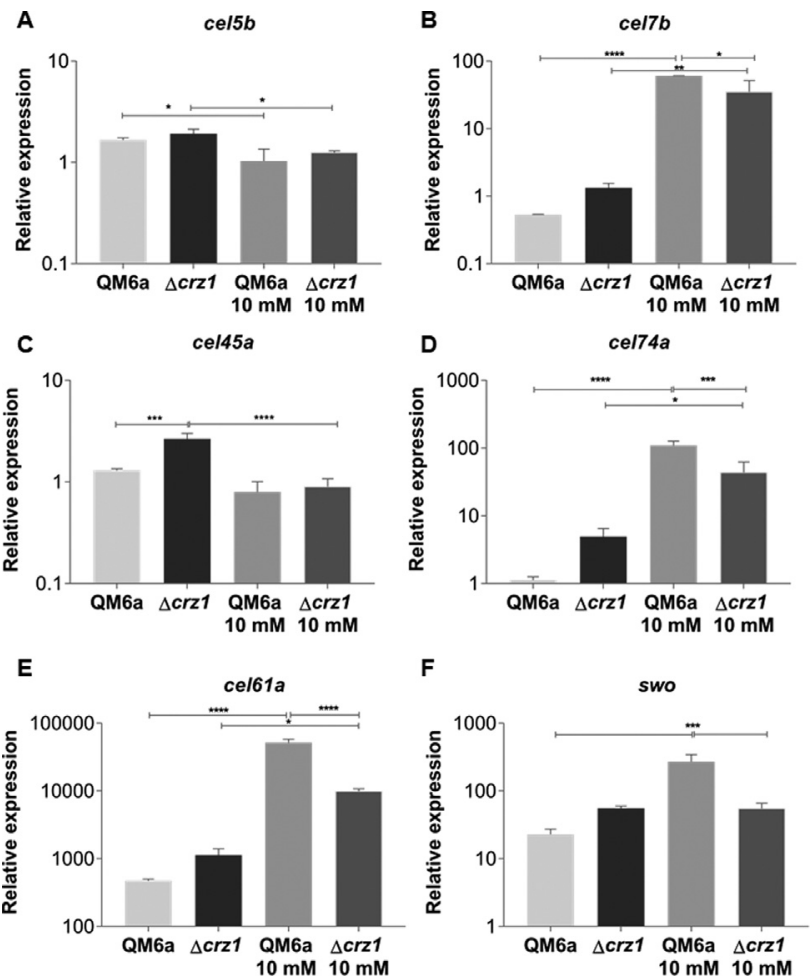

Figure 5 - Analysis of differential expression of the endoglucanases (A-C), xyloglucanase (D), LPMO CEL61A (E) and swollenin (F) from QM6a and $\Delta$ crz1 T. reesei in the presence of SCB and SCB supplemented with $10 \mathrm{mM} \mathrm{Ca}^{2+}$ after $8 \mathrm{~h}$ of induction. Expression values are represented as $\log _{10}$ means of three biological replicates with standard deviation normalized by glycerol expression levels at the same condition. Statistical significance is represented as asterisks, considering p-value as $<0.05\left(^{*}\right)$, $<0.01(* *),<0.001(* * *)$ and $\mathrm{p}<0.0001(* * * *)$.

Finally, once we observed that carbon source could influence the transcription of holocellulases genes in $T$. reese $i$ in $\Delta c r z l$ strain, we studied the effects of crzl knockout on the expression of sugar transporter genes both after SCB and cellulose induction. Interestingly, our results showed that CRZ1 itself plays a regulatory role on the expression of these genes in the presence of complex substrates, since we detected a significant decrease on their expression in the wild type strain in comparison to the mutant strain both grown in SCB (Figure $6 \mathrm{D}-\mathrm{F})$. At the same conditions, we also observed a double effect on the synergic $\mathrm{Ca}^{2+}$ - CRZ1-independent mechanism. In this sense, $\mathrm{Ca}^{2+}$ allied to CRZ1 absence, were able to significantly decrease the expression of Trire_50894 and Trire_60945 genes, while the opposite effect was achieved by the increase of Trire 79202 gene expression. In contrast, concerning cellulose-induced differential regulation, we did not detect any differences on expression of the evaluated genes (Figure S7 C-E), suggesting a remarkable role of CRZ1 in the regulation of genes involved in biomass transport.

\section{Effect of $c r z 1$ deletion on enzymatic activity of holocellulases}

The analysis of the culture supernatants where the QM6a wild type and $\Delta c r z 1$ strains were grown showed that
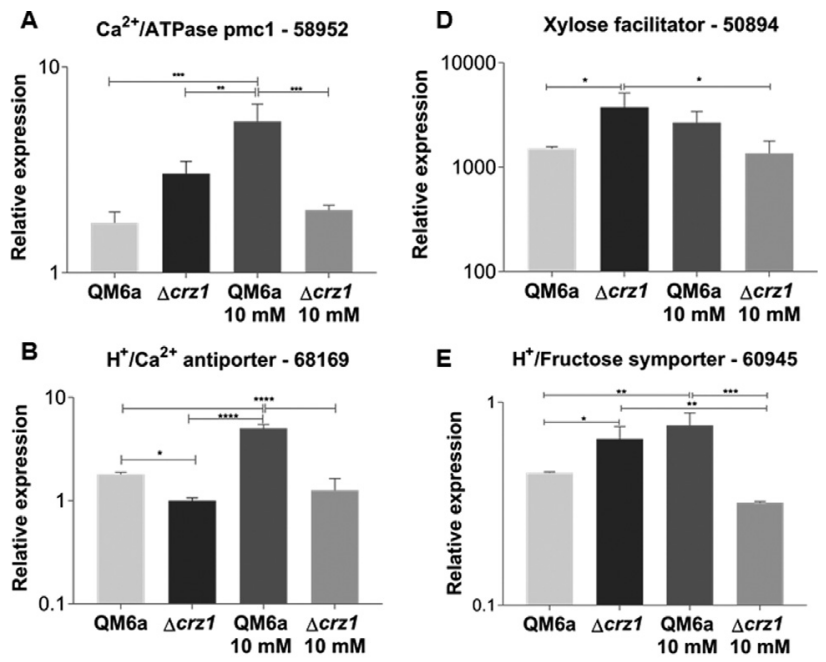

E $\quad \mathrm{H}^{+} /$Fructose symporter -60945
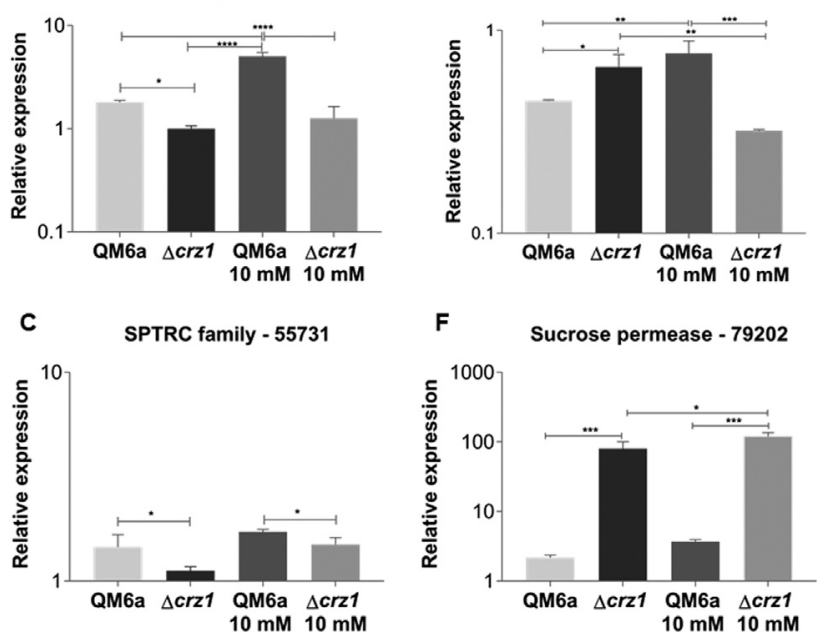

Figure $6-\mathrm{Ca}^{2+}$ transporter genes (A-C) and sugar transporter (D-F) differential genic expression in the QM6a and $\Delta \mathrm{crz} 1 \mathrm{~T}$. reesei strains after $8 \mathrm{~h}$ of growing in SCB and SCB supplemented with $10 \mathrm{mM} \mathrm{Ca}^{2+}$. Results are expressed as $\log _{10}$ means of three biological replicates with standard deviation normalized by glycerol expression levels at the same condition. Statistical significance is represented as asterisks, considering p-value as $<0.05(*),<0.01(* *),<0.001(* * *)$ and $p<0.0001(* * *)$. Protein ID of the evaluated genes are supported at $T$. reesei genome database (https://genome.jgi.doe.gov/pages/search-for-genes.jsf?organism=Trire2 https://genome.jgi.doe.gov/pages/search-for-genes.jsf?organism=Trire2).

the activity of cellulases ( $\beta$-glucosidases and endoglucanases) was always superior in the supernatants from $\Delta c r z l$ strain in comparison to the QM6a strain, regardless the carbon source that we evaluated (Figure 7A-B, Figure S8 A-B). $\mathrm{Ca}^{2+}$ supplementation in the absence of CRZ1 was able to influence the enzymatic activity of the tested supernatants, mainly for endoglucanases, as we were not able to detect any enzymatic activity in the QM6a strain even in the presence of $10 \mathrm{mM}$ $\mathrm{Ca}^{2+}$ for both carbon sources that we investigated.

For xylanase activities ( $\beta$-xylosidases and endoxylanases) in SCB and cellulose (Figure 7C-D, Figure S8 C-D), we observed that in the $\Delta c r z 1$ supernatants the activities were higher compared to the QM6a strain except for the $\beta$-xylosidase in SCB (Figure 7C). Interestingly, the enzymatic activities of supernatants whose QM6a strains were grown after $\mathrm{Ca}^{2+}$ addition were higher in presence of SCB (Figure 7C-D) and presented a decrease in cellulose induction in comparison to SCB supernatants (Figure S8 C-D). For instance, the crz 1 knockout resulted in supernatants with lower $\beta$-xylosidase activity in SCB presence (Figure 7C) and higher xylanases activities measures after cellulose induction (Figure S8 C-D) when compared to the QM6a strain at the same condition. 

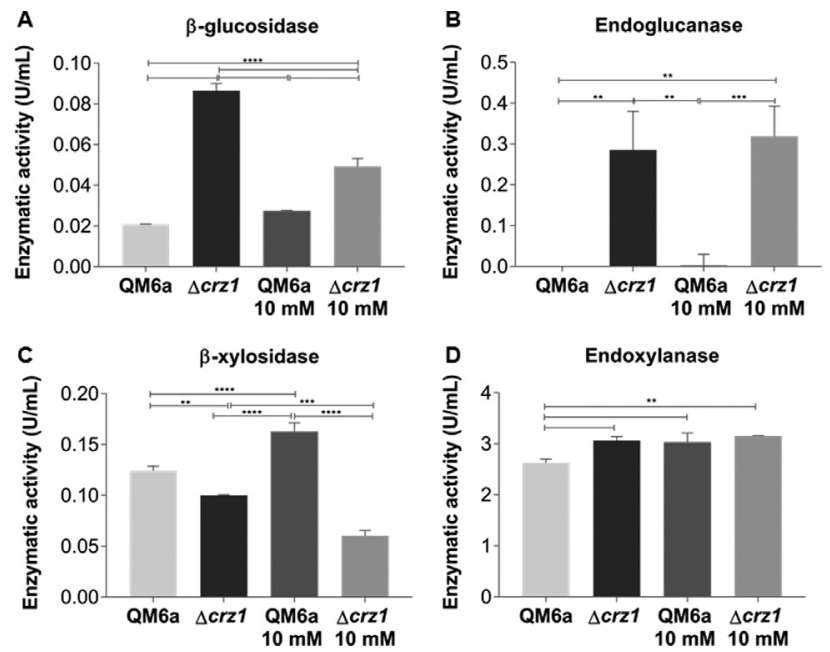

Figure 7 - Enzymatic activity of $\beta$-glucosidase (A), endoglucanase (B), $\beta$-xylosidase (C) and endoxylanase (D) from QM6a and $\Delta$ crz1 T. reesei strains supernatants after $8 \mathrm{~h}$ of growing in SCB and SCB supplemented with $10 \mathrm{mM} \mathrm{Ca}^{2+}$. Results are represented as absolute values in units per milliliter and are representative of a mean of three biological replicates with standard deviation. Statistical significance is represented as asterisks, considering p-value as $<0.05(*),<0.01(* *),<0.001(* * *)$ and $\mathrm{p}<0.0001$ $(* * * *)$.

\section{Discussion}

In this work, we investigated the role of the CRZ1 regulator over the expression of holocellulases and sugar and $\mathrm{Ca}^{2+}$ transporters of the WT T. reesei QM6a strain. CRZ1 is an important regulator involved in several cellular functions in cell and $\mathrm{Ca}^{2+} / \mathrm{CRZ1-Calcineurin/Calmodulin}$ is one of the best studied signaling pathways which provides protection and sensibility for fungal cells against stress conditions. This signaling pathway is already reported to confer $\mathrm{Ca}^{2+}$ and cell wall stress tolerance in Aspergillus (Shwab et al., 2019), pH responsiveness in S. cerevisiae (Roque et al., 2016), and it is related to C. neoformans viability (Lev et al., 2012; Chow et al., 2017). In addition, it is also reported that CRZ1 may influence regulatory mechanisms that control holocellulases expression in T. reesei (Chen et al., 2016).

In this study, we performed bioinformatics approaches to search for putative CRZ1 binding sites in promoter regions of holocellulases, $\mathrm{Ca}^{2+}$ and sugar transporter coding genes in T. reesei QM6a. This approach was achieved considering the sequences in promoter regions of genes whose differential expression was previously reported (Castro et al., 2016). Here we identified that these genes harbored sense and antisense CRZ1 putative binding sites at their ATG upstream sequences and it supports the evidence of the regulation played by this TF independently of carbon source availability. To be clear that CRZ1 was involved in gene regulation in the wild type strain of $T$. reesei, our study reports that holocellulases genes were directly or indirectly modulated by this protein, corroborating the occurrence of putative CRZ1 binding sites sequences in the $T$. reesei genome.
Chen et al. (2016) reported the influence of CRZ1 and $\mathrm{Ca}^{2+}$ on the transcription regulation of some relevant vegetal biomass deconstructing enzymes in the industrial strain $T$. reesei RUT-C30. This seminal work provided the first evidence that the Calcineurin-CRZ1 pathway was related to holocellulases production in this species. However, it was not elucidated whether the other holocellulases genes were target of regulation in this pathway, as this study was performed using the RUT-C30 industrial strain of $T$. reesei (which does not harness CRE1, the master regulator of CCR in this fungus). Since $T$. reesei is gifted with a vast repertoire of such enzymes, this motivated us to investigate the influence of CRZ1 and $\mathrm{Ca}^{2+}$ on the expression of the reminiscent genes, whose expression had not been investigated yet. Therefore, we also were interested in study if the supplementation of complex carbon sources could trigger a differential pattern of sugar transporters expression due to the high amount of distinct sugars present in SCB culture supernatant.

In this sense, we observed that distinct classes of holocellulases were differentially expressed regardless the fungal growth condition. Although cellulose was not capable to modulate a major number of genes independent of CRZ1 presence, SCB provided the major number of differentially expressed genes after its induction process (Figure 8A). This inducer capacity of SCB over the industrial strain RUT-C30 of $T$. reese $i$ was already reported (Borin et al., 2015). In their study, Borin et al. (2015) found 24 biomass degrading enzymes in T. reesei's RUT-C30 secretome after SCB exposure, showing that this carbon source is a potential activator of holocellulases production in this fungus. Interestingly, in our work, SCB induction was able to elicit a higher holocellulases transcriptional response in comparison to cellulose (Figure 8A).

We also observed a major number of differentially expressed genes in the presence of SCB supplemented with $\mathrm{Ca}^{2+}$ in the comparison to cellulose exposure at the same $\mathrm{Ca}^{2+}$ concentration (Figure 8A), endorsing the previously reported effect of carbon source on modulation of $T$. reesei transcriptional profile (Castro et al., 2014b). We observed that $\mathrm{Ca}^{2+}$ seems to be critical for the expression of many holocellulases genes more directly than the carbon source whose fungal growth was previously established, emphasizing its crucial role on transcription of these genes. These evidences strongly confirm the synergistic effect of $\mathrm{Ca}^{2+}$ on the expression of well-studied holocellulases (Chen et al., 2016) and highlight new findings observed for holocellulases genes which had not been studied yet (here described).

$\mathrm{Ca}^{2+}$ plays a regulatory role on several mechanisms in $T$. reesei, e.g. on protein secretion (Mach et al., 1998) and on events related to the CRZ1-Calcineurin pathway (Chen et al., 2016). In this sense, Chen et al. (2016) reported the influence of $5 \mathrm{mM} \mathrm{Ca}^{2+}$ on the transcription of relevant industrial genes of $T$. reesei RUT-C30, such as $c b h 1$ and $x y r 1$. In our study, 10 $\mathrm{mM} \mathrm{Ca}^{2+}$ was able to potentialize the expression of $x y r l$ at the first $8 \mathrm{~h}$ of induction. Our results differ from previous findings reported by Chen et al. (2016) since we used the double of $\mathrm{Ca}^{2+}$ concentration and a longer induction time than the former work (whose study showed the first $6 \mathrm{~h}$ of cellulose expo- 

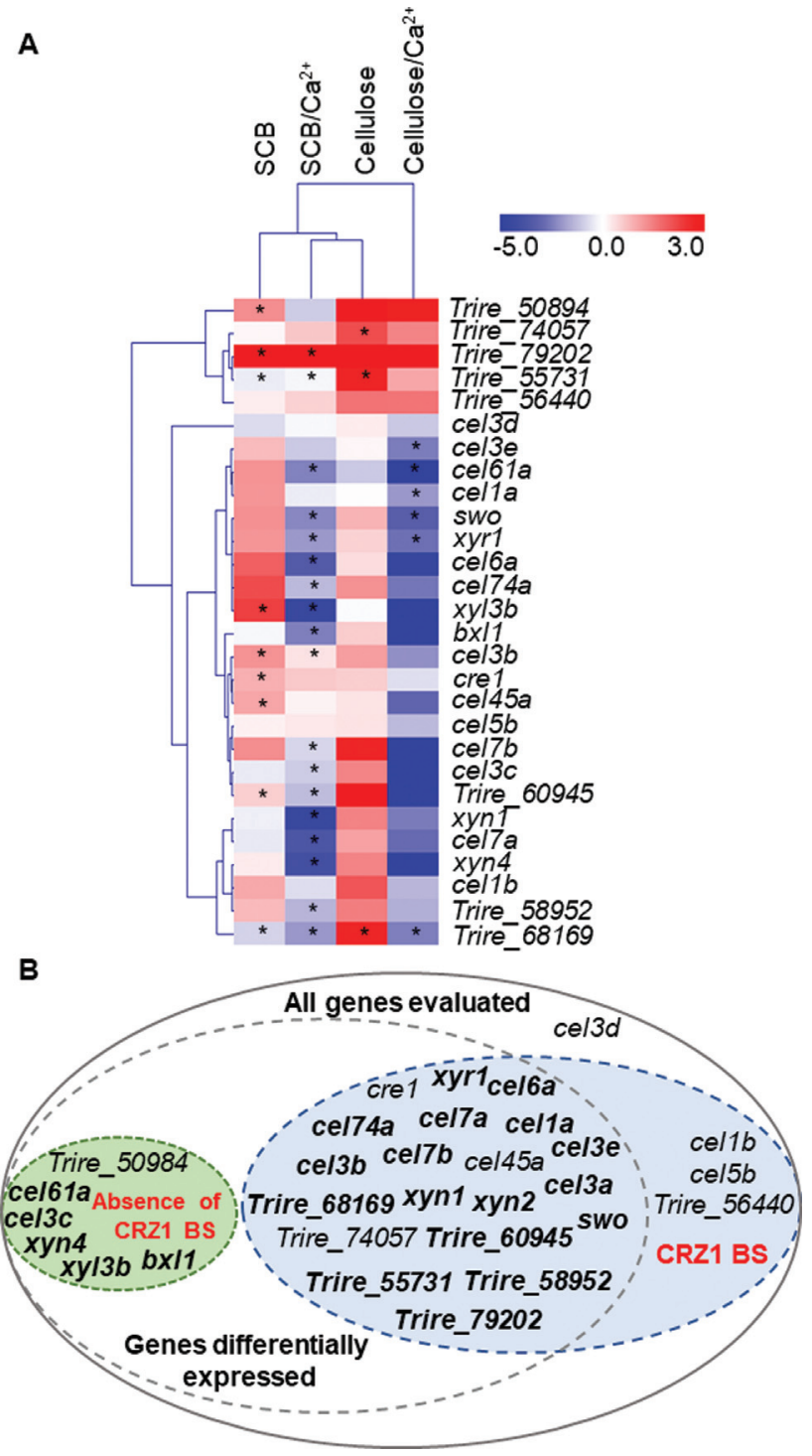

Figure 8 - (A) Heatmap of the differential expression profile of the holocellulases and calcium and transporter sugars after $8 \mathrm{~h}$ of induction in the presence or in the absence of $10 \mathrm{mM} \mathrm{Ca}^{2+}$. Values are representative of the expression obtained with mutant $\mathrm{crz}$ l strain related to the QM6a strain. Genes presenting representative statistical significance are show with asterisks. ID codes for calcium and sugar transporters are supported in $T$. reesei genome database (https://genome.jgi.doe.gov/Trire2/Trire2.home.htm). (B) Representative scheme of genes differentially expressed in the absence of CRZ1 in $T$. reese $i$ and its relation to the occurrence or absence of binding sites (BS) for CRZ1 at genomic level. Bold characters represent the genes whose expression was modulated by $10 \mathrm{mM} \mathrm{Ca}^{2+}$ addition

sure as inefficient to increase expression of $x y r 1$ in the industrial strain of $T$. reesei). Taking this advantage, here we suggest that a higher $\mathrm{Ca}^{2+}$ concentration might elicit a faster gene activation in the presence of cellulose. Interestingly, we also observed a massive loss in transcription of $x y r l$ in our $\Delta c r z l$ strain in the presence of $\mathrm{Ca}^{2+}$, in accordance with the results obtained by Chen et al. (2016).

In the face of the character of regulatory proteins, our results clearly showed that CRZ1 may act as a bifunctional regulator, assuming different profiles both in activation or in the repression of holocellulases in the wild type strain of $T$. reesei, not only playing a specific activating or repressing role over gene expression. We consider this a relevant characteristic for the engineering of $T$. reesei, especially when taking the advantage of the use of SCB as an inducer of holocellulases gene expression, as SCB is an agroindustrial residue that can be widely employed for biofuel production, especially in Brazil, which leads sugarcane bagasse production worldwide.

Our results also show that CRZ1-mediated regulation was not limited to lignocellulose degrading enzymes coding genes, but also intersected the regulatory network that coordinates holocellulases expression in T. reesei QM6a. Therefore, we report that CRZ1 can modulate the transcript levels of relevant TFs such as XYR1 and CRE1 (inactive in RUT-C30 background). The relevance of CRE1 repression is also target of discussion of $T$. reesei regulation. Here we found that CRZ1 positively modulates the expression of CRE1, suggesting that CRZ1 may synergistically contribute to the modulation of holocellulases expression. For instance, we reiterate that the results which we obtained are related to the presence of CRE1 in the WT T. reesei genome, suggesting that different perspectives could be achieved with deeper studies highlighting the interaction between CRZ1 and CRE1 (or its lack).

Albeit the effect of SCB on enzyme expression, $\mathrm{Ca}^{2+}$ and sugar transporter proteins had already been reported in a T. reesei RUT-C30 gene co-expression network study by Borin et al. (2018), here we firstly described the seminal importance of $\mathrm{Ca}^{2+}$ on the expression of sugar transporters in a CRZ1 synergistic context in the T. reesei QM6a strain. According to our data, we hypothesize that under $\mathrm{Ca}^{2+}$ exposure, T. reesei QM6a may coordinate the transcription of sugar transporters to keep metabolic homeostasis through the $\mathrm{Ca}^{2+}$ CRZ1/Calcineurin pathway. This is particularly interesting when the expression pattern was significantly modulated in the presence of SCB, suggesting that complex sugars could induce a fine mechanism of regulation in order to balance the uptake of carbohydrates in the presence of complex sugar-enriched medium.

In addition, our results indicate that the synergic effect of CRZ1 and $\mathrm{Ca}^{2+}$ was also relevant for the regulation of $\mathrm{Ca}^{2+}$ transporters in our study strain. We were able to detect not only the influence of such cooperative effect, but also the carbon-source dependence modulation effect over the transcription of such genes. By this we mean that $\mathrm{Ca}^{2+}$ can potentialize the transcription of $\mathrm{Ca}^{2+}$ transporters in a carbon dependent availability. In summary, we hypothesize that the differential expression of sugar transporters could modulate the uptake of sugars, which in turn, could influence the expression of $\mathrm{CRZ1}$, that, in the presence of $\mathrm{Ca}^{2+}$, could elicit a response to increase the number of $\mathrm{Ca}^{2+}$ transporters to keep cellular homeostasis.

Enzymatic activity of culture supernatants was also widely variable in the distinct strains that we evaluate. We attribute this to the bimodal character of CRZ1, as it could directly or indirectly modulate transcription of enzyme genes. Even though a relation between transcription and translation is not always direct, the activity of $\beta$-xylosidases is signifi- 
cantly reduced in the mutant strain of $\mathrm{crzl}$ in the presence of $\mathrm{Ca}^{2+}$, suggesting that the synergic effect $\mathrm{CRZ} 1-\mathrm{Ca}^{2+}$ may be suggestive of an indirect mechanism of regulation on the activity of these enzymes. Additionally, it is important to consider that $\mathrm{Ca}^{2+}$ could modulate the enzymatic activity of supernatant enzymes and this relation is a deep layer of biochemical analysis in any study.

The effect of sense or antisense CRZ1 putative binding sites in promoter regions is one of the main evidences that supports regulation in the QM6a strain of T. reesei. The effect of arrangements and repetitions of TFs binding sites in $T$. reese $i$ was already reported by Kiesenhofer et al. (2018) as an important parameter for engineering transcriptional regulation in this fungus. As observed in our work, through an in silico analysis, from the total set of differentially expressed genes, only 6 of them did not harness CRZ1 putative binding sites and only one of these was not modulated by $\mathrm{Ca}^{2+}$ (Figure 8B). These evidences strongly suggest that the synergistic mechanism played by CRZ1 and $\mathrm{Ca}^{2+}$ is required for holocellulases and transporter coding genes expression in $T$. reesei QM6a even not in the presence of stress conditions. In addition, our data also assert that CRZ1 activation is pivotal for gene regulation, but $\mathrm{Ca}^{2+}$ is determinant for an increasing modulation (positive or negative) on gene expression levels, emphasizing the necessity of deeper studies on indirect holocellulases regulation in $T$. reesei.

Finally, we summarize the importance of investigating CRZ1 role on the expression of holocellulases in $T$. reesei. Deeper studies are necessary to a fully understand the network comprising CRZ1 and $\mathrm{Ca}^{2+}$, and according to our results, we also suggest that there is may be another unknown regulatory pathway directly or indirectly responsive to $\mathrm{Ca}^{2+}$ and this could influence CRZ1 regulatory role in an indirect manner.

\section{Conclusions}

In this study, we used bioinformatics approaches to search for putative TFs in relevant industrial genes of $T$. reesei. Here we demonstrate the huge potential of in silico methods to explore transcription regulation in important enzyme biofactories, mainly in industrial filamentous species. In summary, we describe the construction of a $T$. reesei $\mathrm{crz} 1$ knockout strain through bioinformatics prediction and validation of the regulatory role of the bifunctional CRZ1 protein on transcriptional regulation of $T$. reesei. Allied to $\mathrm{Ca}^{2+}$, an important modulator of the regulatory effects of CRZ1, holocellulases and calcium/sugar transporter genes can be positively or negatively modulated in a CRZ1- synergistic mechanism, as well as the enzymatic activity of such enzymes may direct or indirectly be affected by CRZ1 regulatory role. These phenomena are suitable attributes to biotechnological industry applications, highlighting fungi engineering as a fundamental platform to enzyme production at large scale.

\section{Acknowledgments}

This work was supported by two current projects funding. RS-R was supported by the São Paulo Research Foundation (FAPESP, award number 2012/22921-8). LM-S was supported by FAPESP PhD Fellowship (award number 2017/17924-1).

\section{Conflict of Interests}

The authors declare that there are no conflict of interests.

\section{Author Contributions}

LM-S performed the experimental design, experimental procedures, analysis of results and drafted the paper. AGS performed bioinformatics analysis of promoter sequences. RGP performed experimental design and experimental procedures concerning qRT-PCR. DCBL performed experimental procedures concerning enzymatic activities and analyzed the obtained results. RNS supervised the experimental design and contributed to the manuscript drafting and preparation. RSR supervised experimental analysis, prepared and drafted the final version of the manuscript. All the authors have read and approved the final version to submission.

\section{References}

Antoniêto AC, de Paula RG, Castro LS, Silva-Rocha R, Persinoti GF and Silva RN (2016) Trichoderma reesei CRE1-mediated carbon catabolite repression in response to sophorose through RNA sequencing analysis. Curr Genomics. 17:119-131.

Aro N, Ilme M, Saloheimo A and Penttila M (2003) ACEI of Trichoderma reesei is a repressor of cellulase and xylanase expression. Appl Environ Microbiol 69:56-65.

Aro N, Saloheimo A, Ilme M and Penttila M (2001) ACEII, a novel transcriptional activator involved in regulation of cellulase and xylanase genes of Trichoderma reesei. J Biol Chem 276:24309-24314.

Borin GP, Carazzolle MF, Augusto R, Riaño-pachón DM, Velasco J, Oliveira DC and Silva R (2018) Gene co-expression network reveals potential new genes related to sugarcane bagasse degradation in Trichoderma reesei RUT-30. Front Bioeng Biotechnol 6:115.

Borin GP, Sanchez CC, de Souza AP, de Santana S, de Souza AT, Paes Leme AF, Squina FM, Buckeridge M, Goldman GH et al. (2015) Comparative secretome analysis of Trichoderma reesei and Aspergillus niger during growth on sugarcane biomass. PLoS One 10:e0129275.

Cao Y, Zheng F, Wang L and Zhao G (2017) Rce1, a novel transcriptional repressor, regulates cellulase gene expression by antagonizing the transactivator Xyr1 in Trichoderma reesei. Mol Microbiol 105:65-83.

Castro LDS, Antoniêto ACC, Pedersoli WR, Silva-Rocha R, Persinoti GF and Silva RN (2014a) Expression pattern of cellulolytic and xylanolytic genes regulated by transcriptional factors XYR1 and CRE1 are affected by carbon source in Trichoderma reesei. Gene Expr Patterns 14:88-95.

Castro LS, de Paula RG, Antoniêto ACC, Persinoti GF, SilvaRocha R and Silva RN (2016) Understanding the role of the master regulator XYR1 in Trichoderma reesei by global transcriptional analysis. Front Microbiol 7:175.

Castro S, Pedersoli WR, Antoniêto ACC, Steindorff AS, SilvaRocha R, Martinez-Rossi NM, Rossi A, Brown NA, Goldman GH, Faça VM et al. (2014b) Comparative metabolism 
of cellulose, sophorose and glucose in Trichoderma reesei using high-throughput genomic and proteomic analyses. Biotechnol Biofuels 7:41.

Chen L, Zou G, Wang J, Wang J, Liu R, Jiang Y, Zhao G and Zhou $\mathrm{Z}$ (2016) Characterization of the $\mathrm{Ca} 2+$-responsive signaling pathway in regulating the expression and secretion of cellulases in Trichoderma reesei Rut-C30. Mol Microbiol 100:560-575.

Chow EWL, Clancey SA, Billmyre RB, Averette AF, Granek JA, Mieczkowski P, Cardenas ME and Heitman J (2017) Elucidation of the calcineurin-Crz1 stress response transcriptional network in the human fungal pathogen Cryptococcus neoformans. PLoS Genet 13:e1006667.

Christianson TW, Sikorski RS, Dante M, Shero JH and Hieter P (1992) Multifunctional yeast high-copy-number shuttle vectors. Gene 110:119-122.

Collopy PD, Colot HV, Park G, Ringelberg C, Christopher M, Borkovich KA and Dunlap JC (2010) High-throughput construction of gene deletion cassetes for generation of Neurospora crassa knockout strains. Methods Mol Biol 638:33-40.

Colot HV, Park G, Turner GE, Ringelberg C, Crew CM, Litvinkova L, Weiss RL, Borkovich KA and Dunlap JC (2006) A high-throughput gene knockout procedure for Neurospora reveals functions for multiple transcription factors. Proc Natl Acad Sci U S A 103:10352-10357.

De Boer CG and Hughes TR (2012) YeTFaSCo: A database of evaluated yeast transcription factor sequence specificities. Nucleic Acids Res 40:D169-D179.

de Paula RG, Antoniêto ACC, Ribeiro LFC, Carraro CB, Nogueira KMV, Lopes DCB, Silva AC, Zerbini MT, Pedersoli WR, Costa MDN et al. (2018) New genomic approaches to enhance biomass degradation by the industrial fungus Trichoderma reesei. Int J Genomics 2018:1974151.

de Souza WR, Gouvea PF, Savoldi M, Malavazi I, Bernades LADS, Goldman MHS, de Vries RP, Oliveira JVDC and Goldman GH (2011) Transcriptome analysis of Aspergillus niger grown on sugarcane bagasse. Biotechnol Biofuels 4:40.

Derntl C, Kiesenhofer DP, Mach RL and Mach-Aigner AR (2015a) Novel strategies for genomic manipulation of Trichoderma reesei with the purpose of strain engineering. Appl Environ Microbiol 81:6314-6323.

Derntl C, Rassinger A, Srebotnik E, Mach RL and Aigner ARM (2015b) Xpp1 regulates the expression of xylanases, but not of cellulases in Trichoderma reesei. Biotechnol Biofuels 8:112.

Druzhinina IS and Kubicek CP (2017) Genetic engineering of Trichoderma reesei cellulases and their production. Microb Biotechnol 10:1485-1499.

Gietz RD and Schiestl RH (2007) High-efficiency yeast transformation using the LiAc/SS carrier DNA/PEG method. Natur Protocols 2:31-34.

Goldman GH, Savoldi M, Semighini CP, Oliveira RC De, Nunes LR, Travassos LR, Puccia R, Batista WL, Ferreira LE, Bogossian AP et al. (2003) Expressed sequence tag analysis of the human pathogen Paracoccidioides brasiliensis yeast phase: identification of putative homologues of Candida albicans virulence and pathogenicity genes. Eukaryot Cell 2:34-48.

Gruber F, Visser J, Kubicek CP and de Graaff LH (1990) The development of a heterologous transformation system for the cellulolytic fungus Trichoderma reesei based on a pyrGnegative mutant strain. Curr Genet 18:71-76.
Gupta VK, Steindorff AS, de Paula RG, Silva-Rocha R, MachAigner AR, Mach RL and Silva RN (2016) The post-genomic era of Trichoderma reesei: What's next? Trends Biotechnol 34:970-982.

He R, Ma L, Li C, Jia W, Li D, Zhang D and Chen S (2014) Trpac1, a $\mathrm{pH}$ response transcription regulator, is involved in cellulase gene expression in Trichoderma reesei. Enzyme Microb Technol 67:17-26.

Hideno A, Inoue H, Tsukahara K, Yano S, Fang X, Endo T and Sawayama S (2011) Production and characterization of cellulases and hemicellulases by Acremonium cellulolyticus using rice straw subjected to various pretreatments as the carbon source. Enzyme Microb Technol 48:162-168.

Karimi RA, Németh Z, Atanasova L, Fekete E, Paholcsek M, Sándor E, Aquino B, Druzhinina IS, Karrafa L and Kubicek CP (2014) The VELVET A orthologue VEL1 of Trichoderma reesei regulates fungal development and is essential for cellulase gene expression. PLoS One 9: e112799.

Kiesenhofer DP, Mach RL and Mach-Aigner AR (2018) Influence of cis element arrangement on promoter strength in Trichoderma reesei. Appl Environ Microbiol 84: e0174217.

Lev S, Desmarini D, Chayakulkeeree M, Sorrell TC and Djordjevic JT (2012) The Crz1/Sp1 transcription factor of Cryptococcus neoformans is activated by calcineurin and regulates cell wall integrity. PLoS One 7:e51403.

Liu R, Chen L, Jiang Y, Zou G and Zhou Z (2017) A novel transcription factor specifically regulates GH11 xylanase genes in Trichoderma reesei. Biotechnol Biofuels 10:194.

Livak KJ and Schmittgen TD (2001) Analysis of relative gene expression data using real-time quantitative PCR and the 2- $\triangle \Delta C T$ method. Methods 25:402-408.

Lopes FAC, Steindorff AS, Geraldine AM, Brandão RS, Monteiro VN, Júnior ML, Coelho ASG, Ulhoa CJ and Silva RN (2012) Biochemical and metabolic profiles of Trichoderma strains isolated from common bean crops in the Brazilian Cerrado, and potential antagonism against Sclerotinia sclerotiorum. Fungal Biol 116:815-824.

Mach RL, Zeilinger S, Kristufek D and Kubicek CP (1998) $\mathrm{Ca} 2+$-calmodulin antagonists interfere with xylanase formation and secretion in Trichoderma reesei. Biochim Biophys Acta 1403:281-289.

Martins-Santana L, Nora LC, Sanches-Medeiros A, Lovate GL, Cassiano MHA and Silva-Rocha R (2018) Systems and synthetic biology approaches to engineer fungi for fine chemical production. Front Bioeng Biotechnol 6:117.

Mello-de-Sousa TM, Gorsche R, Rassinger A, Poças-Fonseca MJ, Mach RL and Mach-Aigner AR (2014) A truncated form of the Carbon catabolite repressor 1 increases cellulase production in Trichoderma reesei. Biotechnol Biofuels 7:129.

Miller GL (1959) Use of dinitrosalicylic acid reagent for determination of reducing sugar. Anal Chem 31:426-428.

Moreno-Mateos MA and Codo AC (2007) pH and Pacl control development and antifungal activity in Trichoderma harzianum. Fungal Genet Biol 44:1355-1367.

Nitta M, Furukawa T, Shida Y, Mori K, Kuhara S and Morikawa Y (2012) A new Zn (II) 2 Cys 6 -type transcription factor BglR regulates $\mathrm{b}$-glucosidase expression in Trichoderma reesei. Fungal Genet Biol 49:388-397.

Portnoy T, Margeot A, Linke R, Atanasova L, Fekete E, Sándor E, Hartl L, Karaffa L, Druzhinina IS, Seiboth B et al. (2011) 
The CRE1 carbon catabolite repressor of the fungus Trichoderma reesei: a master regulator of carbon assimilation. BMC Genomics 12:269.

Prasad S, Singh A and Joshi HC (2007) Ethanol as an alternative fuel from agricultural, industrial and urban residues. Resour Conserv Recycl 50:1-39.

Roque A, Petrezsélyová S, Serra-Cardona A and Ariño J (2016) Genome-wide recruitment profiling of transcription factor Crz1 in response to high $\mathrm{pH}$ stress. BMC Genomics 17:662.

Santos M and de Larrinoa IF (2005) Functional characterization of the Candida albicans CRZ1 gene encoding a calcineurinregulated transcription factor. Curr Genet 48:88-100.

Sambrook J and Russel DW (2001) Molecular cloning: A laboratory manual. Cold Spring Harbor Laboratory Press, New York, vol. 2.

Schmoll M, Dattenböck C, Carreras-Villaseñor N, MendozaMendoza A, Tisch D, Alemán MI, Baker SE, Brown C, Cervantes-Badillo MG, Cetz-Chel J et al. (2016) The genomes of three uneven siblings: Footprints and lifestyles of three Trichoderma species. Microbiol Mol Biol Rev 80:205-327.

Schmoll M, Schuster A, Silva RDN and Kubicek CP (2009) The G-alpha protein GNA3 of Hypocrea jecorina (anamorph Trichoderma reesei) regulates cellulase gene expression in the presence of light. Eukaryot Cell 8:410-420.

Schuster A, Bruno KS, Collett JR, Baker SE, Seiboth B, Kubicek CP and Schmoll M (2012) A versatile toolkit for high throughput functional genomics with Trichoderma reesei. Biotechnol Biofuels 5:1.

Seiboth B, Karimi RA, Phatale PA, Linke R, Hartl L, Sauer DG, Smith KM, Baker SE, Freitag M and Kubicek CP (2012) The putative protein methyltransferase LAE1 controls cellulase gene expression in Trichoderma reesei. Mol Microbiol 84:1150-1164.

Seidl V, Gamauf C, Druzhinina IS, Seiboth B, Hartl L and Kubicek CP (2008) The Hypocrea jecorina (Trichoderma reesei) hypercellulolytic mutant RUT C30 lacks a 85 kb (29 gene-encoding) region of the wild-type genome. BMC Genomics 9:327.

Seppälä S, Wilken SE, Knop D, Solomon KV and O'Malley MA (2017) The importance of sourcing enzymes from non-conventional fungi for metabolic engineering and biomass breakdown. Metab Eng 44:45-59.

Shwab EK, Juvvadi PR, Waitt G, Soderblom EJ, Barrington BC, Asfaw YG, Moseley MA and Steinbach WJ (2019) Calcineurin-dependent dephosphorylation of the transcription factor CrzA at specific sites control conidiation, stress tolerance, and virulence of Aspergillus fumigatus. Mol Microbiol $112: 62-80$.

Soriani FM, Malavazi I, da Silva Ferreira ME, Savoldi M, Von Zeska Kress MR, de Souza Goldman MH, Loss O, Bignell E and Goldman GH (2008) Functional characterization of the Aspergillus fumigatus CRZ1 homologue, CrzA. Mol Microbiol 67:1274-1291.

Stricker AR, Grosstessner-Hain K, Wu E and Mach RL (2006) Xyr1 (xylanase regulator 1) regulates both the hydrolytic en- zyme system and D -xylose metabolism in Hypocrea jecorina. Eukaryot Cell 5:2128-2137.

Thewes S (2014) Calcineurin-Crz1 signaling in lower eukaryotes. Eukaryot Cell 13:694-705.

Virgilio S, Cupertino FB, Ambrosio DL and Bertolini MC (2017) Regulation of the reserve carbohydrate metabolism by alkaline $\mathrm{pH}$ and calcium in Neurospora crassa reveals a possible cross-regulation of both signaling pathways. BMC Genomics 18:457.

Vitikainen M, Arvas M, Pakula T, Oja M, Penttilä M and Saloheimo M (2010) Array comparative genomic hybridization analysis of Trichoderma reesei strains with enhanced cellulase production properties. BMC Genomics 11:441.

Xiao Z, Storms R and Tsang A (2005) Microplate-based carboxymethylcellulose assay for endoglucanase activity. Anal Biochem 342:176-178.

Zakrzewska A, Boorsma A, Brul S, Klaas J, Klis FM and Hellingwerf KJ (2005) Transcriptional response of Saccharomyces cerevisiae to the plasma membrane-perturbing compound chitosan. Eukaryot Cell 4:703-715.

Zeilinger S, Ebner A, Marosits T, Mach R and Kubicek CP (2001) The Hypocrea jecorina HAP 2/3/5 protein complex binds to the inverted CCAAT-box (ATTGG) within the cbh2 (cellobiohydrolase II-gene) activating element. Mol Gen Genomics 266:56-63.

Zhang T, Xu Q, Sun X and Li H (2013) The calcineurin-responsive transcription factor Crz1 is required for conidation, full virulence and DMI resistance in Penicillium digitatum. Microbiol Res 168:211-222.

\section{Supplementary Material}

The following online material is available for this article:

Table S1 - Primers used in this study for the construction of the crzl deletion cassete.

Table S2 - Primers used in this study for real time PCR.

Figure S1 - Molecular procedures to confirm crz1 ORF deletion from T. reesei QM6a genome.

Figure S2 - Expression profile of regulators and main cellulase from $T$. reesei.

Figure S3 - Expression of holocellulases in response to Avicel. Relative expression of

Figure S4 - Expression of $\beta$-glucosidases genes of $T$. reesei.

Figure S5 - Expression of endoglucanases and accessory proteins.

Figure S6 - Expression of transporter genes.

Figure S7 - Expression of transporters in response to SCB and Avicel.

Figure S8 - Expression of additional holocellulases in response to Avicel.

Associate Editor: Célia Soares.

License information: This is an open-access article distributed under the terms of the Creative Commons Attribution License (type CC-BY), which permits unrestricted use, distribution and reproduction in any medium, provided the original article is properly cited. 